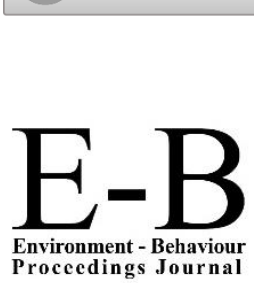

\author{
ASLI QoL 2017 \\ AicQoL2017Bangkok \\ $5^{\text {th }}$ AMER International Conference on Quality of Life \\ Nouvo City Hotel, Bangkok, Thailand, 25-27 February 2017
}

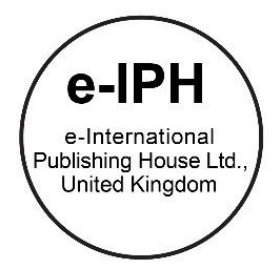

\title{
Predictors of Breastfeeding Intention in Malaysia
}

\author{
Syahrul Bariah Abdul Hamid *1, Jun HC2, Binns CW2 \\ 1 Faculty of Health Sciences, UiTM Puncak Alam, Selangor, Malaysia \\ ${ }^{2}$ School of Public Health, Faculty of Health Science, Curtin University, Perth
}

\begin{abstract}
Breastfeeding is linked to a number of health related benefits among infants. Breastfeeding provides the ideal nutrition for infants, by promoting a higher IQ and protecting against childhood and adult diseases. Despite these health benefits, the rates of exclusive breastfeeding are still low in Malaysia. Intention to breastfeed is closely related to early initiation to breastfeed and could also be a predictor of longer duration of breastfeeding. The objectives of this study are to provide a descriptive analysis of the sociodemographic characteristics, breastfeeding intention and breastfeeding attitudes and determine predictors affecting breastfeeding intention among low-to-middle income women. A prospective cohort study was undertaken of mothers attending eight antenatal clinics run by the Ministry of Health in Selangor, Malaysia. Mothers were recruited during the antenatal period and followed up until six months postpartum to document breastfeeding outcomes. Among 652 mothers in our study, exclusive breastfeeding, mixed feeding, and exclusive formula feeding intentions were $49.6 \%, 46.3 \%$, and $9.0 \%$, respectively. Age, maternal employment, maternal education, parity, pre-pregnancy body mass index (BMI), breastfeeding attitude, spouse's preference, grandmother's preference and breastfeeding experience had significant relationship with breastfeeding intention $(p<0.05)$. However, further analysis showed that breastfeeding intention was associated with positive breastfeeding attitudes, older age, greater years of education, being housewives, having partner and family support for breastfeeding and grandmothers' breastfeeding experience. These findings suggest that by providing breastfeeding initiatives towards less educated, young mothers who lack breastfeeding support from their loved ones may improve breastfeeding rates.
\end{abstract}

Keywords: Exclusive breastfeeding; Maternal obesity; Breastfeeding intention; Breastfeeding attitude

ISSN: 2398-42870 2017. The Authors. Published for AMER ABRA by e-International Publishing House, Ltd., UK. This is an open access article under the CC BYNC-ND license (http://creativecommons.org/licenses/by-nc-nd/4.0/. Peer-review under responsibility of AMER (Association of Malaysian Environment-Behaviour Researchers), ABRA (Association of Behavioural Researchers on Asians) and cE-Bs (Centre for Environment-Behaviour Studies), Faculty of Architecture, Planning \& Surveying, Universiti Teknologi MARA, Malaysia.

\subsection{Introduction}

Breastmilk is the most complete nutrition for infants (Gartner et al., 2005). Breastfeeding provides significant protective effect towards various childhood diseases to the infants in the short term and beyond (Binns, Lee, \& Low, 2016; Horta \& Victora, 2013). Infants who were not breastfeeding may expose to higher risks of infectious morbidity, as well as associated with increased risks of childhood obesity, leukemia, type I and II diabetes and sudden infant death syndrome (SIDs) (Stuebe, 2009). Breastfeeding intention is a significant predictor of positive breastfeeding outcomes, having an intention to breastfeed linked to early initiation and longer duration of breastfeeding (Donath \& Amir, 2003; Mitra, Khoury, Hinton, \& Carothers, 2004; Tarrant, Younger, Sheridan-Pereira, White, \& Kearney, 2010a). Intention is an immediate precursor of behaviour and is defined as the perception of an individual towards performance of a particular behaviour (Ajzen \& Fishbein, 1980). In this study breastfeeding intention was defined as the degree of confidence about practising optimal breastfeeding behaviour. Intention to breastfeed is closely related to early initiation to breastfeed and could also be a predictor of longer duration of breastfeeding (Tarrant, Younger, Sheridan-Pereira, White, \& Kearney, 2010b).

Many studies have documented there are various factors associated with breastfeeding intention (Kavanagh, Lou, Nicklas, Habibi, \& Murphy, 2012; McLnnes, Love, \& Stone, 2001; Mitra et al., 2004; Persad \& Mensinger, 2008). These factors include maternal age,

\footnotetext{
${ }^{*}$ Corresponding author. Tel.:

E-mail address: syahrulbariah25@gmail.com
}

ISSN: 2398-4287@ 2017. The Authors. Published for AMER ABRA by e-International Publishing House, Ltd., UK. This is an open access article under the CC BYNC-ND license (http://creativecommons.org/licenses/by-nc-nd/4.0/). Peer-review under responsibility of AMER (Association of Malaysian Environment-Behaviour Researchers), ABRA (Association of Behavioural Researchers on Asians) and cE-Bs (Centre for Environment-Behaviour Studies), Faculty of Architecture, Planning \& Surveying, Universiti Teknologi MARA, Malaysia. DOI: http://dx.doi.org/10.21834/e-bpj.v2i5.693 
education status, household income, parity, marital status, being breastfed before, mother's knowledge on the benefits of breastfeeding, mother's attitude towards breastfeeding and social support network received by mothers. Interestingly, various studies have suggested that higher body mass index (BMI) was associated with adverse breastfeeding outcomes. In a recent systematic review, it is advocated that obese women were less likely intend to breastfeed their infants and were linked to decreased initiation of breastfeeding, shorter duration of breastfeeding, inadequate milk supply and delayed onset of lactogenesis II as compared to their normal weight counterparts (Turcksin, Bel, Galjaard, \& Devlieger, 2014).

Meanwhile, in the Third National Health and Morbidity Survey did in 2006, reported that $19.3 \%$ and $14.5 \%$ of infants were exclusively breastfed up to four months and six months, respectively. These figures were actually decreased from the Second National Health and Morbidity Survey that was done 10 years before. Prevalence of 'exclusive breastfeeding' at 4 months was $29.0 \%$ (Fatimah S, Jackie H, Tahir A, Yusof MI \& Sa'adiah HN, 1999).

Hence, by considering the factors associated with intention to breastfeed may provide a better understanding to the policy health makers on ways to improve breastfeeding initiation and duration through appropriate interventions. Therefore, this study aimed to investigate the level of attitude and intention to breastfeed and determine the predictors of intention to breastfeed in this population.

\subsection{Methodology}

\subsection{Study population}

This study was conducted between September 2013 and April 2015. A sample of 652 expecting women with singleton pregnancies, aged between 18 to 40 years old was included in this study. Selangor is the most populous state in Malaysia with 5.46 million persons in 2011. This study centres on three major districts in Selangor which were Petaling, Klang and Gombak. Shah Alam and Sungai Buloh were both located in Petaling district. Shah Alam was the most greatly populated with 1,812,633 people, followed by Sungai Buloh $(1,765,49)$, Klang $(861,189)$ and Gombak $(682,226)$ as tabulated by the Department Statistics of Malaysia (Department of Statistics, 2011). Meanwhile, Malay ethnic group was the majority population with $2,754,826$ (55.8 \%) followed by Chinese (28.6 \%: $1,410,690)$, Indians (13.5\%: 664,591) and other indigenous. A prospective cohort design is used to study mothers selected from ten selected government Mother and Child Health clinics from these three large districts.

\subsection{Data collection}

Expectant mothers were first recruited during their antenatal examination at the selected government Mother \& Child Health Clinics. Upon agreement to participate in this study, three sets of questionnaires on socio-demographics, as well as baseline questions on infant feeding intention and lowa Infant Feeding Attitude Scale (IIFAS) to assess woman's infant feeding attitude were asked. The IIFAS consists of 17-item questions to measure attitudes and knowledge of mothers (la Mora, Russell, Dungy, Losch, \& Dusdieker, 1999). Mothers will be asked to indicate the extent which they agree with each statement on a 5-point Likert scale ranging from 1 (strongly disagree) to 5 (strongly agree). There were approximately half the items were worded favourably towards breastfeeding and the remaining favour formula feeding. Items that were favoured on formula feeding were reverse-scored and a total score is computed by summing all items. Total attitude scores range from 17 to 85 with a higher score reflecting attitudes more positive to breastfeeding. Total scores are grouped into the following three categories: (1) positive to breastfeeding (70-85), (2) neutral (49-69), and (3) positive to formula feeding (17-48). It has been translated in Malay and was back-translated into English to ensure the original version and the second language (Malay) version has the same meaning and concepts.

\subsection{Data analysis}

Data were analysed using the Statistical Package for Social Sciences (SPSS) windows version 20.0. Comparison between numbers of women who intended to breastfeed antenatally and socio-demographic characteristics was done using Chi-square test. Multivariate binary logistic regression analyses were executed to determine the variables related to the intention to breastfeed among the mothers. A two-sided level of significance of 0.05 was used.

\subsection{Results}

\subsection{Characteristics of the participants}

A total of 652 women participated in this study. The age of participants ranged from 18 and 40 years old with the mean age was 29.03 years old. Selected participant demographic data are reported in Table 1.

Almost all of the mothers were married $(99.5 \%)$, and the majority were working fulltime $(60.6 \%)$, had a tertiary education (57.2 \%), had household incomes between RM 1001 and RM 3000 (49.5\%) and these were their first pregnancy (39.9\%). At the same time as the majority of the spouses were fulltime workers $(82.5 \%)$ and had a tertiary education $(57.2 \%)$.

\subsection{Intention to breastfeed}

Only $49.4 \%$ of the mothers intended to exclusively breastfeed their infants. Factors associated with intention to breastfeed were classified into maternal and paternal socio-demographic, maternal knowledge and psychosocial as shown in Table 2. Breastfeeding intention was more common among young mothers (less than 30 years old), higher educated and employed women, women with one 
child, women with normal pre-pregnancy BMI, women with higher educated partners, women who had positive attitudes towards breastfeeding, women who had breastfeeding supports from partners and biological mothers and women who had previous breastfeeding exposure.

Table 1 Characteristic of the subjects

\begin{tabular}{|c|c|c|c|}
\hline Variables & Categories & $\mathbf{N}$ & $\%$ \\
\hline \multirow[t]{2}{*}{ Age (years) } & $18-30$ years old & 420 & 64.7 \\
\hline & $31-40$ years old & 230 & 35.3 \\
\hline \multirow[t]{2}{*}{ Marital status } & Married & 649 & 99.5 \\
\hline & Never married/Divorced/Separated & 3 & 0.5 \\
\hline \multirow[t]{3}{*}{ Household income } & Low $(<\mathrm{RM} 3000)$ & 331 & 53.5 \\
\hline & Middle (RM 3001 - 5000) & 137 & 21.0 \\
\hline & $>$ RM 5000 & 166 & 25.5 \\
\hline \multirow[t]{2}{*}{ Maternal educational background } & $\leq 12$ years & 238 & 36.5 \\
\hline & $>12$ years & 411 & 63.0 \\
\hline \multirow[t]{2}{*}{ Maternal Employment status } & Housewife & 202 & 31.0 \\
\hline & Employed & 444 & 68.7 \\
\hline \multirow[t]{3}{*}{ Parity } & $1^{\text {st }}$ child & 260 & 39.9 \\
\hline & 2 children & 206 & 31.6 \\
\hline & 3 or more children & 178 & 27.3 \\
\hline \multirow[t]{2}{*}{ Breastfeeding husband support } & Yes & 443 & 67.9 \\
\hline & No, or were ambivalent & 206 & 31.6 \\
\hline \multirow[t]{2}{*}{ Breastfeeding family support } & Yes & 387 & 59.4 \\
\hline & No, or were ambivalent & 262 & 40.2 \\
\hline \multirow[t]{2}{*}{ Breastfeeding intention } & Yes & 322 & 49.4 \\
\hline & No & 327 & 50.2 \\
\hline
\end{tabular}

Table 2 Breastfeeding intention and socio-demographic characteristics

\begin{tabular}{|c|c|c|c|c|c|}
\hline \multirow[t]{2}{*}{ Characteristics } & \multicolumn{2}{|c|}{ With intention to EBF, $n=322$} & \multicolumn{2}{|c|}{ Without intention to EBF, $n=327$} & \multirow[t]{2}{*}{$P$ value } \\
\hline & $n$ & $\%$ & $n$ & $\%$ & \\
\hline \multicolumn{6}{|l|}{ Demographic factors } \\
\hline Household monthly income & & & & & 0.615 \\
\hline Low $(<\mathrm{RM} 3000)$ & 166 & 51.6 & 181 & 55.4 & \\
\hline Middle (RM3001 - 5000) & 70 & 21.7 & 67 & 20.5 & \\
\hline High ( $\geq$ RM5000) & 86 & 26.7 & 79 & 24.2 & \\
\hline Parity & & & & & $<0.001^{*}$ \\
\hline Primiparous & 180 & 56.8 & 79 & 24.4 & \\
\hline Multiparous & 137 & 43.2 & 245 & 75.6 & \\
\hline \multicolumn{6}{|l|}{ Maternal factors } \\
\hline Age during pregnancy & & & & & $<0.001^{*}$ \\
\hline $18-30$ years old & 248 & 77.0 & 172 & 52.6 & \\
\hline $31-40$ years old & 74 & 23.0 & 155 & 47.4 & \\
\hline Years of education & & & & & $<0.001^{*}$ \\
\hline$\leq 12$ years & 97 & 30.1 & 141 & 43.1 & \\
\hline$>12$ years & 225 & 69.9 & 186 & 56.9 & \\
\hline Employment & & & & & $0.013^{*}$ \\
\hline Housewife & 114 & 35.5 & 88 & 27.1 & \\
\hline Employed & 207 & 64.5 & 237 & 72.9 & \\
\hline Pre-pregnancy BMI & & & & & $0.035^{\star}$ \\
\hline Normal (BMI 18.5 - 24.9 kg/m2) & 216 & 67.1 & 196 & 59.9 & \\
\hline Overweight and obese $(\mathrm{BMl}>25)$ & 106 & 32.9 & 131 & 40.1 & \\
\hline \multicolumn{6}{|l|}{ Paternal factors } \\
\hline Years of education & & & & & $<0.001^{*}$ \\
\hline$\leq 12$ years & 115 & 35.8 & 162 & 49.7 & \\
\hline$>12$ years & 206 & 64.2 & 164 & 50.3 & \\
\hline Employment & & & & & 0.493 \\
\hline Unemployed & 3 & 0.9 & 2 & 0.6 & \\
\hline Employed & 318 & 99.1 & 324 & 99.4 & \\
\hline \multicolumn{6}{|l|}{ Maternal knowledge } \\
\hline IIFAS score & & & & & $0.023^{*}$ \\
\hline Low $(<65)$ & 159 & 49.4 & 135 & 41.3 & \\
\hline $\operatorname{High}(\geq 65)$ & 163 & 50.6 & 192 & 58.7 & \\
\hline Attending breastfeeding interventions & & & & & 0.296 \\
\hline Yes & 257 & 80.6 & 269 & 82.5 & \\
\hline No & 62 & 19.4 & 57 & 17.5 & \\
\hline Attending antenatal class & & & & & 0.282 \\
\hline Yes & 236 & 73.3 & 232 & 70.9 & \\
\hline No & 86 & 26.7 & 95 & 29.1 & \\
\hline \multicolumn{6}{|l|}{ Psychosocial factors } \\
\hline Father's preference & & & & & $<0.001^{*}$ \\
\hline Breastfeeding & 248 & 77.0 & 195 & 59.6 & \\
\hline Formula feeding or ambivalent & 74 & 23.0 & 132 & 40.4 & \\
\hline Grandmother's preference & & & & & $<0.001^{*}$ \\
\hline
\end{tabular}




\begin{tabular}{|c|c|c|c|c|c|}
\hline Breastfeeding & 214 & 66.5 & 173 & 52.9 & \multirow{5}{*}{$0.004^{*}$} \\
\hline Formula feeding or ambivalent & 108 & 33.5 & 154 & 47.1 & \\
\hline Grandmother's breastfeeding experience & & & & & \\
\hline Yes & 237 & 73.6 & 208 & 63.6 & \\
\hline No & 85 & 26.4 & 119 & 36.4 & \\
\hline
\end{tabular}

\subsection{Factors associated with breastfeeding intention}

The multivariate analysis of factors associated with intention to breastfeed is shown in Table 3 . Women aged less than 30 years, higher educated, being housewives, women with positive attitudes towards breastfeeding, women with supportive partners and biological mothers and had previous exposure in breastfeeding were more likely to intend to exclusively breastfeed their infants.

Table 3 Odds ratios and $95 \%$ confidence intervals for the factors significantly associated with positive intention to breastfeed, adjusted for demographic variables ${ }^{\text {a }}$

\begin{tabular}{|c|c|c|}
\hline Factors & $\begin{array}{c}\text { Adjusted Odds Ratios } \\
\text { (95\% Confidence Interval) }\end{array}$ & $P$ value \\
\hline \multicolumn{3}{|l|}{ Maternal factors } \\
\hline \multicolumn{3}{|l|}{ Maternal age } \\
\hline $18-30$ years old & $2.096(1.428-3.078)$ & $<0.001^{*}$ \\
\hline 31 to 40 years old & 1 & \\
\hline \multicolumn{3}{|l|}{ Maternal years of education } \\
\hline$\leq 12$ years & 1 & $0.005^{*}$ \\
\hline$>12$ years & $1.648(1.164-2.333)$ & \\
\hline \multicolumn{3}{|l|}{ Maternal employment } \\
\hline Housewives & $2.105(1.372-3.230)$ & $0.001^{*}$ \\
\hline Employed & 1 & \\
\hline \multicolumn{3}{|l|}{ Paternal factors } \\
\hline \multicolumn{3}{|l|}{ Years of education } \\
\hline$\leq 12$ years & $1.666(1.172-2.368)$ & $0.004^{*}$ \\
\hline$>12$ years & 1 & \\
\hline \multicolumn{3}{|l|}{ Demographic factor } \\
\hline \multicolumn{3}{|l|}{ Household monthly income } \\
\hline Low (<RM 5000) & $0.948(0.612-1.470)$ & 0.813 \\
\hline High ( $\geq$ RM5000) (ref) & 1 & \\
\hline \multicolumn{3}{|l|}{ Maternal knowledge } \\
\hline \multicolumn{3}{|l|}{ IIFAS score } \\
\hline High ( $\geq 65)$ & $1.444(1.030-2.025)$ & $0.033^{*}$ \\
\hline Low $(<65)$ & 1 & \\
\hline \multicolumn{3}{|l|}{ Attending breastfeeding interventions } \\
\hline Yes & $1.053(0.675-1.643)$ & 0.905 \\
\hline No & 1 & \\
\hline \multicolumn{3}{|l|}{ Attending antenatal class } \\
\hline Yes & $1.281(0.875-1.877)$ & 0.203 \\
\hline No & 1 & \\
\hline \multicolumn{3}{|l|}{ Psychosocial factors } \\
\hline \multicolumn{3}{|l|}{ Father's preference } \\
\hline Breastfeeding & $2.381(1.639-3.458)$ & $<0.001^{*}$ \\
\hline Formula feeding or ambivalent & 1 & \\
\hline \multicolumn{3}{|l|}{ Grandmother's preference } \\
\hline Breastfeeding & $1.700(1.212-2.384)$ & $0.002^{*}$ \\
\hline Formula feeding or ambivalent & 1 & \\
\hline \multicolumn{3}{|c|}{ Grandmother's breastfeeding experience for more than 1 month } \\
\hline Yes & $1.657(1.157-2.371)$ & $0.006^{*}$ \\
\hline No & 1 & \\
\hline
\end{tabular}

\subsection{Discussion}

This study showed the majority of the mothers had intended to breastfeed their infants $(96.0 \%)$, only $49.4 \%$ had intended to breastfeed exclusively. Though $39.9 \%$ of the mothers were first-time mothers with no experience in breastfeeding, their early decision would pose a positive outcome in breastfeeding. A study by Donath \& Amir had shown that the time intended to breastfeed was important in predicting breastfeeding initiation and duration (Donath \& Amir, 2003).

There was also found no difference in intended to breastfeed by BMI categories $(p=0.226)$, nevertheless, more than half of the mothers who had the intention to breastfeed were normal BMI $(51.6 \%)$. The majority of the mothers decided to breastfeed their newborns during pregnancy with the highest number were mothers with normal BMI (51.7\%). 
This is supported by a study done by Hauff and friends in 2014, they found out that BMl category was not independently associated with intention to breastfeed; nevertheless, obese women tend to have lower chances of 'ever breastfeeding' and pose a greater risk of an earlier cessation of 'exclusive' and "any breastfeeding" (Hauff, Leonard, \& Rasmussen, 2014a).

This finding is also aligned with a study done in Illinois to examine the factors affecting their choice of infant-feeding method and attitudes toward breastfeeding done by Dix in 1991 among 81 women, a total of $46 \%$ of them made their decision during pregnancy whereas, $41 \%$ of them decided before conception (Dix, 1991). There was no difference in intended duration of breastfeeding (in women who intended to breastfeed) by BMI category, nevertheless, intended to breastfeed for a longer period had a significantly lengthier median duration of "exclusive breastfeeding" as well as "any breastfeeding" (Hauff, Leonard, \& Rasmussen, 2014b).

In this study, expecting mothers were more likely to intend to breastfeed if they have a higher score in IIFAS which reflects a positive attitude towards breastfeeding. This finding consistent with studies done in United States (Persad \& Mensinger, 2008), United Kingdom (Shaker, Scott, \& Reid, 2004), Ireland (Sittlington, Stewart-Knox, Wright, Bradbury, \& Scott, 2007), Canada (Twells et al., 2014) and Korea (Kang, Choi, Hyun, \& Lee, 2015) who found that breastfeeding intention is associated with positive breastfeeding attitudes.

The findings of this study also suggested that pregnant women were more likely intend to breastfeed if they had previous breastfeeding experience or exposure. Both studies were done by Mclnnes et al. and Humphreys et al. reported that previous breastfeeding experience was one of the significant determinants of breastfeeding intention (Dungy, Mclnnes, Tappin, Wallis, \& Oprescu, 2008; Humphreys, Thompson, \& Miner, 1998).

Our study provides strong evidence that pregnant women who perceived their partners had support from their partners in breastfeeding were more likely having the intention to breastfeed exclusively. Various studies suggest that presence of supportive spouses/partners are important in playing a critical role in the mothers decision on how to feed the infant (Nemeh Ahmad Al-Akour, Khassawneh, Khader, Ababneh, \& Haddad, 2010; Kong \& Lee, 2004; Scott, Binns, \& Aroni, 1997) by encouraging them to breastfeed their newborn infants (Wolfberg et al., 2004). Fathers can play their roles as breastfeeding advocates which in turn will promote initiation and increase the duration of breastfeeding (Wolfberg et al., 2004) as well as boosting higher confidence in breastfeeding along the journey (Mannion, Hobbs, McDonald, \& Tough, 2013).

Since breastfeeding journey will have their ups and downs experienced by of the mothers especially for the new mothers, it is also important that fathers should be exposed on how to prevent and manage the most common lactation difficulties might face by the mothers, for example, breasts engorgement and latching problems.

In a controlled trial study done in Italy, 280 fathers were divided into two; there will be a training session on management of breastfeeding in the intervention group and control group where they received nothing. As a result, the intervention group had higher rates of 'full breastfeeding' at 6 months (25\%) compared to only $15 \%$ in control group. Furthermore, majority mothers of intervention groups $(91 \%)$ reported receiving an adequate amount of support and relevant assistance in infant feeding management from their partners compared to control group (34 \%) (Pisacane, Continisio, Aldinucci, D'Amora, \& Continisio, 2005).

Interestingly, this study suggested that biological mothers play an important role in mother's decision to infant feeding choice. As supported by Kessler et al., women's intention to breastfeed is also strongly affected by the mother's significant other's infant feeding preferences which in turn may result in successful breastfeeding initiation (Kessler, Gielen, Diener-West, \& Paige, 1995).

Our finding also indicated that maternal age may influence women's intention to breastfeed, mothers who aged less than 30 years old were more likely to intend to breastfeed. This is supported by a study done on Jordanian and Syrian women, they found Syrian women aged 25 or less had more intention to breastfeed compared to the older aged women (Nemeh Ahmad Al-Akour et al., 2010). This is might be due to increase awareness in breastfeeding among young mothers through social networks, media and introduction of benefits of breastfeeding in the academic curriculum. However, few studies reported older maternal age as the predictive factor of breastfeeding intention (Dungy et al., 2008; Forster, McLachlan, \& Lumley, 2006; Mitra et al., 2004).

The present study showed that higher education was associated with breastfeeding intention among the mothers. This finding is aligned with a study done in the United States (Colaizy, Saftlas, \& Morriss, 2012). Colaizy et al. found that mothers who had higher education were more likely had the intention to breastfeed their babies. In contrast, another study from Jordan (N A Al-Akour, Khassawneh, Khader, Ababneh, \& Haddad, 2010), they found out that lower education was significantly associated with breastfeeding intention. This difference between Malaysia and other countries can be explained by mothers with higher educated were more aware of the importance of breastfeeding as well as they are more likely to seek further information about breastfeeding from social networks, media and also it has been part of the academic curriculum.

However, this study suggested that housewives were more likely intended to breastfeed as compared to working mothers. Our results are consistent with the findings from a study done in United States, full-time employed mothers were less likely to fulfil their intention to exclusively breastfeed their babies compared to unemployed mothers (Attanasio, Kozhimannil, McGovern, Gjerdingen, \& Johnson, 2013). In contrast to other study done by Bakoula et al., the study found that working mothers had more intention to breastfeed and breastfeed longer than housewives. The lengthier the mothers entitled to maternity leave, the longer duration of breastfeeding (Bakoula et al., 2007). The dissimilarity can be explained by housewives were more likely intending to breastfeed due to economic restrain and they had extra bonding time with their babies as compared to working mothers. In addition, mothers who are not employed are more likely to initiate breastfeeding (Poduval \& Poduval, 2009) and continue to breastfeed longer than employed mothers (Ryan, Zhou, \& Arensberg, 2006).

This study provided information regarding breastfeeding intention among Malaysian mothers. The findings of this study emphasise the importance of social support (partners and biological mothers) for positive breastfeeding intention. Health policy makers in Malaysia can benefit the findings from this study in increasing the rates of exclusive breastfeeding. The results of this study welcome 
further longitudinal studies as well as qualitative studies in providing more insight on the barriers of breastfeeding intention among expectant mothers.

\subsection{Conclusions}

The prevalence of intention to breastfeed is high among Malaysian expecting mothers. Breastfeeding intention was significantly associated with positive breastfeeding attitudes, older age, greater years of education, being housewives, having a partner and family support for breastfeeding and grandmothers' breastfeeding experience. These factors should be considered when planning for further interventions in promoting exclusive breastfeeding in Malaysia.

In summary, having an intention to breastfeed during prenatal has significantly contributed to positive attitudes towards breastfeeding among mothers as well as providing an influence on both initiation and duration of breastfeeding (Al-Akour, Khassawneh, Khader, Ababneh, and Haddad, 2010; Amir and Donath, 2007; Donath and Amir, 2003). Mothers who had positive breastfeeding intention prenatally was linked to the longer duration of breastfeeding (Wang, Lau, Chow, and Chan, 2014) and prenatal intention appears to be significant predictors of breastfeeding initiation and duration (Donath and Amir, 2003).

\section{Acknowledgements}

This project was funded by the School of Public Health, Faculty of Health Sciences, Curtin University, Australia and Lestari Research Grant (600-IRMI/DANA 5/3/LESTARI(0101/2016) provided by Institute of Research Management and Innovation, MARA University of Technology, Selangor, Malaysia.

\section{References}

Ajzen, I., \& Fishbein, M. (1980). Understanding attitudes and predicting social behavior. EnglewoodCliffs NY Prentice Hall (Vol. 278). http://doi.org/Z

Al-Akour, N. A., Khassawneh, M. Y., Khader, Y. S., Ababneh, A. A., \& Haddad, A. M. (2010). Factors affecting intention to breastfeed among Syrian and Jordanian mothers: a comparative cross-sectional study. Int Breastfeed J, 5. http://doi.org/10.1186/1746-4358-5-6

Al-Akour, N. A., Khassawneh, M. Y., Khader, Y. S., Ababneh, A. A., \& Haddad, A. M. (2010). Factors affecting intention to breastfeed among Syrian and Jordanian mothers: a comparative cross-sectional study. International Breastfeeding Journal, 5, 6. http://doi.org/10.1186/1746-4358-5-6

Amir, L. H., \& Donath, S. (2007). A systematic review of maternal obesity and breastfeeding intention, initiation and duration. BMC Pregnancy and Childbirth, 7, 9. http://doi.org/10.1186/1471-2393-7-9

Attanasio, L., Kozhimannil, K. B., McGovern, P., Gjerdingen, D., \& Johnson, P. J. (2013). The impact of prenatal employment on breastfeeding intentions and breastfeeding status at 1 week postpartum. Journal of Human Lactation : Official Journal of International Lactation Consultant Association, $29(4), 620-8$. http://doi.org/10.1177/0890334413504149

Bakoula, C., Veltsista, A., Prezerakou, A., Moustaki, M., Fretzayas, A., \& Nicolaidou, P. (2007). Working mothers breastfeed babies more than housewives. Acta Paediatrica, International Journal of Paediatrics, 96(4), 510-515. http://doi.org/10.1111/j.1651-2227.2006.00185.x

Binns, C., Lee, M., \& Low, W. Y. (2016). The Long-Term Public Health Benefits of Breastfeeding. Asia-Pacific Journal of Public Health, 28(1), 7-14. http://doi.org/10.1177/1010539515624964

Colaizy, T. T., Saftlas, A. F., \& Morriss, F. H. (2012). Maternal intention to breast-feed and breast-feeding outcomes in term and preterm infants: Pregnancy Risk Assessment Monitoring System (PRAMS), 2000-2003. Public Health Nutrition, 15(4), 702-10. http://doi.org/10.1017/S1368980011002229

Department of Statistics. (2011). Population Distribution and Basic Demographic Characteristic Report 2010. Retrieved September 16, 2016, from https://www.statistics.gov.my/index.php?r=column/ctheme\&menu_id=LOpheU43NWJwRWVSZkIWdzQ4TIhUUT09\&bul_id=MDMxdHZjWTk1SjFzTzNkRXYzcVZjdz09

Dix, D. N. (1991). Why women decide not to breastfeed. Birth (Berkeley, Calif.), 18(4), 222-225. http://doi.org/10.1111/j.1523-536X.1991.tb00105.x

Donath, S. M., \& Amir, L. H. (2003). Relationship between prenatal infant feeding intention and initiation and duration of breastfeeding: a cohort study. Acta Paediatrica, 92, 352-356. http://doi.org/12725552

Dungy, C. I., McInnes, R. J., Tappin, D. M., Wallis, A. B., \& Oprescu, F. (2008). Infant feeding attitudes and knowledge among socioeconomically disadvantaged women in Glasgow. Maternal and Child Health Journal, 12(3), 313-322. http://doi.org/10.1007/s10995-007-0253-9

Fatimah S, Jackie H, Tahir A, Yusof MI, S., \& Sa'adiah HN, L. S. \& M. A. (1999). Breastfeeding among Children below Two Years Old. National Health and Morbidity Survey 1996. Public Health Institute, Ministry of Health Malaysia, 18.

Forster, D. A., McLachlan, H. L., \& Lumley, J. (2006). Factors associated with breastfeeding at six months postpartum in a group of Australian women. International Breastfeeding Journal, 1, 18. http://doi.org/10.1186/1746-4358-1-18

Gartner, L. M., Morton, J., Lawrence, R. A., Naylor, A. J., O'Hare, D., Schanler, R. J., ... American Academy of Pediatrics Section on Breastfeeding. (2005). Breastfeeding and the use of human milk. Pediatrics, 115(2), 496-506. http://doi.org/10.1542/peds.2004-2491

Hauff, L. E., Leonard, S. A., \& Rasmussen, K. M. (2014a). Associations of maternal obesity and psychosocial factors with breastfeeding intention, initiation, and 
duration. American Journal of Clinical Nutrition, 99(3), 524-534. http://doi.org/10.3945/ajcn.113.071191

Hauff, L. E., Leonard, S. A., \& Rasmussen, K. M. (2014b). Associations of maternal obesity and psychosocial factors with breastfeeding intention, initiation, and duration. American Journal of Clinical Nutrition, 99, 524-534. http://doi.org/10.3945/ajcn.113.071191

Horta, B. L., \& Victora, C. G. (2013). Long-term health effects of breastfeeding. World Health Organization (Vol. 129). Retrieved from http://www.ncbi.nlm.nih.gov/pubmed/20960419

Humphreys, A. S., Thompson, N. J., \& Miner, K. R. (1998). Intention to breastfeed in low-income pregnant women: The role of social support and previous experience. Birth, 25(3), 169-174. http://doi.org/10.1046/j.1523-536X.1998.00169.x

Kang, N. M., Choi, Y. J., Hyun, T., \& Lee, J. E. (2015). Associations of Breastfeeding Knowledge, Attitude and Interest with Breastfeeding Duration: A Cross-sectional Web-based Study. Journal of Korean Academy of Nursing, 45(3), 449-458. http://doi.org/10.4040/jkan.2015.45.3.449

Kavanagh, K. F., Lou, Z., Nicklas, J. C., Habibi, M. F., \& Murphy, L. T. (2012). Breastfeeding Knowledge, Attitudes, Prior Exposure, and Intent among Undergraduate Students. Journal of Human Lactation. http://doi.org/10.1177/0890334412446798

Kessler, L. A., Gielen, A. C., Diener-West, M., \& Paige, D. M. (1995). The effect of a woman's significant other on her breastfeeding decision. Journal of Human Lactation, 11(2), 103-109. http://doi.org/10.1177/089033449501100214

Kong, S. K. F., \& Lee, D. T. F. (2004). Factors influencing decision to breastfeed. Journal of Advanced Nursing, 46, 369-379. http://doi.org/10.1111/j.13652648.2004.03003.x

la Mora, A., Russell, D. W., Dungy, C. I., Losch, M., \& Dusdieker, L. (1999). The lowa Infant Feeding Attitude Scale: analysis of reliability and validity. J App/ Soc Psychol, 29. http://doi.org/10.1111/j.1559-1816.1999.tb00115.x

Mannion, C. A., Hobbs, A. J., McDonald, S. W., \& Tough, S. C. (2013). Maternal perceptions of partner support during breastfeeding. International Breastfeeding Journal, 8(1), 4. http://doi.org/10.1186/1746-4358-8-4

McLnnes, R. J., Love, J. G., \& Stone, D. H. (2001). Independent predictors of breastfeeding intention in a disadvantaged population of pregnant women. BMC Public Health, 1, 10. http://doi.org/10.1186/1471-2458-1-10

Mitra, A. K., Khoury, A. J., Hinton, A. W., \& Carothers, C. (2004). Predictors of breastfeeding intention among low-income women. Maternal and Child Health Journal, $8(2), 65-70$

Persad, M. D., \& Mensinger, J. L. (2008). Maternal breastfeeding attitudes: Association with breastfeeding intent and socio-demographics among urban primiparas Journal of Community Health, 33, 53-60. http://doi.org/10.1007/s10900-007-9068-2

Pisacane, A., Continisio, G. I., Aldinucci, M., D’Amora, S., \& Continisio, P. (2005). A controlled trial of the father's role in breastfeeding promotion. Pediatrics, 116(4), e494-e498. http://doi.org/10.1542/peds.2005-0479

Poduval, J., \& Poduval, M. (2009). Working mothers: how much working, how much mothers, and where is the womanhood? Mens Sana Monographs, 7(1), 63-79. http://doi.org/10.4103/0973-1229.41799

Ryan, A. S., Zhou, W., \& Arensberg, M. B. (2006). The effect of employment status on breastfeeding in the United States. Women's Health Issues, 16(5), $243-251$. http://doi.org/10.1016/j.whi.2006.08.001

Scott, J. A., Binns, C. W., \& Aroni, R. A. (1997). The influence of reported paternal attitudes on the decision to breast-feed. Journal of Paediatrics and Child Health, 33(4), 305-307. http://doi.org/10.1111/j.1440-1754.1997.tb01605.x

Shaker, I., Scott, J. A., \& Reid, M. (2004). Infant feeding attitudes of expectant parents: Breastfeeding and formula feeding. Journal of Advanced Nursing, 45, $260-268$. http://doi.org/10.1046/j.1365-2648.2003.02887.x

Sittlington, J., Stewart-Knox, B., Wright, M., Bradbury, I., \& Scott, J. A. (2007). Infant-feeding attitudes of expectant mothers in Northern Ireland. Health Education Research, 22, 561-570. http://doi.org/10.1093/her/cyl113

Stuebe, A. (2009). The Risks of Not Breastfeeding. Reviews in Obstetrics and Gynecology, 2(4), 222-231. http://doi.org/10.3909/riog0093

Tarrant, R. C., Younger, K. M., Sheridan-Pereira, M., White, M. J., \& Kearney, J. M. (2010a). The prevalence and determinants of breast-feeding initiation and duration in a sample of women in Ireland. Public Health Nutrition, 13(6), 760-70. http://doi.org/10.1017/S1368980009991522

Tarrant, R. C., Younger, K. M., Sheridan-Pereira, M., White, M. J., \& Kearney, J. M. (2010b). The prevalence and determinants of breast-feeding initiation and duration in a sample of women in Ireland. Public Health Nutrition, 13, 760-770. http://doi.org/10.1017/S1368980009991522

Turcksin, R., Bel, S., Galjaard, S., \& Devlieger, R. (2014). Maternal obesity and breastfeeding intention, initiation, intensity and duration: a systematic review. Maternal \& Child Nutrition, 10(2), 166-83. http://doi.org/10.1111/j.1740-8709.2012.00439.x

Twells, L. K., Midodzi, W. K., Ludlow, V., Murphy-Goodridge, J., Burrage, L., Gill, N., ... Newhook, L. A. (2014). Assessing Infant Feeding Attitudes of Expectant Women in a Provincial Population in Canada: Validation of the lowa Infant Feeding Attitude Scale. Journal of Human Lactation, 1-10. http://doi.org/10.1177/0890334414559647

Wang, W., Lau, Y., Chow, A., \& Chan, K. S. (2014). Breast-feeding intention, initiation and duration among Hong Kong Chinese women: A prospective longitudinal study. Midwifery, 30, 678-687. http://doi.org/10.1016/j.midw.2013.07.015

Wolfberg, A. J., Michels, K. B., Shields, W., O'Campo, P., Bronner, Y., \& Bienstock, J. (2004). Dads as breastfeeding advocates: Results from a randomized controlled trial of an educational intervention. American Journal of Obstetrics and Gynecology, 191(3), 708-712. http://doi.org/10.1016/j.ajog.2004.05.019 